\title{
O PROBLEMA DE CORTE DE ESTOQUE EM INDÚSTRIAS DE MÓVEIS DE PEQUENO E MÉDIO PORTES
}

\author{
Socorro Rangel* \\ Altamir G. de Figueiredo \\ DCCE / IBILCE \\ Universidade Estadual Paulista (UNESP) \\ S.J. do Rio Preto - SP \\ socorro@,ibilce.unesp.br \\ altamirgf@yahoo.com \\ * Corresponding author / autor para quem as correspondências devem ser encaminhadas \\ Recebido em 05/2007; aceito em 09/2008 após 1 revisão \\ Received May 2007; accepted September 2008 after one revision
}

\begin{abstract}
Resumo
A geração de padrões de corte para cortar painéis retangulares de madeira em itens retangulares menores é uma tarefa rotineira em indústrias de móveis. Além do objetivo usual de minimizar perdas, as indústrias procuram gerar padrões de corte que facilitem o processo de corte. Neste trabalho analisamos os padrões de corte adotados por uma fábrica característica do Pólo Moveleiro de Votuporanga-SP. Propomos uma heurística para a geração de um conjunto de padrões de corte baseados em padrões $n$-grupos e usamos na solução do problema de corte de estoque. Comparamos a solução do método heurístico com a solução obtida através do método em 2-estágios de Gilmore e Gomory e a prática da fábrica. Os resultados obtidos indicam que a heurística proposta é capaz de gerar padrões de corte similares aos utilizados pela fábrica, com índices de perda iguais ou melhores.
\end{abstract}

Palavras-chave: corte de estoque bidimensional; padrões de corte n-grupos; heurística; indústria de móveis.

\begin{abstract}
Defining cutting patterns to cut rectangular plates to produce smaller rectangular pieces with specified sizes and demands is an every day task in the furniture industry. Besides the usual interest in cutting patterns that minimizes waste, there is also interest in developing cutting patterns that allows a rapid manipulation of the plates. In this work we analyze the cutting patterns used in a furniture industry situated at the state of São Paulo-Brazil and present a heuristic procedure to generate cutting patterns based on $n$-group guillotine pattern. We compare the heuristic solution with the solution given by the traditional 2-stage Gilmore-Gomory method and the industry practice. The results indicate that the proposed heuristic can generate cutting patterns similar to the ones used in the industry with waste index that are equal or better.
\end{abstract}

Keywords: two-dimensional cutting stock; n-group cutting pattern; heuristic; furniture industry. 


\section{Introdução}

Problemas de corte e empacotamento aparecem em diversos contextos e têm motivado a comunidade científica nacional e internacional na busca de métodos de solução eficientes. Este interesse pode ser comprovado, por exemplo, na consulta a livros dedicados exclusivamente ao tema (e.g. [MT90], [DF92]), em artigos de revisão e números especiais de revistas nacionais e internacionais (e.g. [DST97], [AMY99], [AMY04], [WW02], [LMM02]), e pela formação de grupos de pesquisa para tratar exclusivamente do tema (e.g. [ESICUP], [GPCE]). Na literatura, é possível também encontrar trabalhos que tratam do problema no contexto da indústria de móveis com foco em empresas de grande porte (e.g. [GF06], [MA00], [CM00], [KKS96]). No presente trabalho, discutimos a aplicação de um caso particular dessa classe de problemas, o problema de corte de estoque bidimensional, em indústrias de móveis de pequeno e médio portes.

A indústria de móveis no Brasil apresenta uma forte dispersão geográfica, porém está concentrada em pólos regionais localizados principalmente nas regiões Sul e Sudeste do país. É predominantemente composta por micro e pequenas empresas. A produção do setor está dividida em três áreas principais: $60 \%$ móveis residenciais, $25 \%$ móveis de escritório e $15 \%$ distribuído entre outros tipos (e.g. institucionais, escolares, médico-hospitalares, restaurantes, hotéis e similares). Essas empresas possuem um processo de produção bastante diverso, indo de empresas com o processo de produção totalmente automatizado nas grandes empresas até produção totalmente manual nas pequenas, sendo comum se encontrar equipamentos modernos e obsoletos sendo usados simultaneamente em uma mesma empresa. Na produção de móveis são usados diferentes tipos de matéria prima (e.g. madeira, metal, plástico, couro), mas em geral, as empresas se especializam em móveis de um único tipo de material. O faturamento do setor tem crescido nos últimos anos e um considerável esforço tem sido desenvolvido para aumentar o volume de exportações [AB05], [St02].

O estado de São Paulo detém cerca de $40 \%$ do faturamento do setor. O maior destaque é para os pólos da região noroeste do estado, voltados principalmente para a produção de móveis residenciais de madeira, onde são gerados mais de 10 mil empregos diretos [Sep03]. Dentre esses pólos, destacamos o Pólo de Votuporanga, que já foi considerado o segundo maior pólo moveleiro do Brasil [Su00], e apesar de representar apenas um pequeno percentual do total de emprego da indústria, é altamente relevante do ponto de vista do desenvolvimento local. Esse pólo moveleiro tem despertado interesse de diversos pesquisadores e entidades (e.g. [LG05], [SS04], [Si03], [St02], [Su00]).

A maioria das empresas fabricantes de móveis do Pólo de Votuporanga é de pequeno e médio portes caracterizadas por uma grande diversidade no grau de organização das mesmas. A formação desse pólo e o grau de desenvolvimento alcançado se devem a diversos fatores. A criação da Associação Industrial da Região de Votuporanga (AIRVO) em meados da década de 1970 permitiu identificar que uma boa parcela dos problemas que dificultavam o crescimento do setor na época advinha do fato que a maioria dos proprietários conheciam bem o processo de produção, porém faltava ainda conhecimento nas áreas de gerência, planejamento da produção, e formas de inserção no mercado. Para sanar parte destes problemas, diversas iniciativas foram tomadas pelos empresários nas décadas de 1980 e 1990. Entre elas a criação de um centro de formação que permitisse a geração e transmissão de conhecimento sobre gestão da produção moveleira. Assim, através de um processo de articulação que envolveu a comunidade local, além de governos e entidade nacionais foi constituído o Centro de Formação Profissional da Madeira e do Mobiliário (CEMAD), 
inaugurado em 2001. Outra iniciativa importante foi a criação do curso Superior em Tecnologia da Produção Moveleira oferecido pela Fundação Educacional de Votuporanga (FEV). A capacidade empreendedora dos trabalhadores da região gerou uma expansão da indústria moveleira na região. A articulação entre as empresas do setor possibilitou o desenvolvimento de políticas de qualidade e qualificação profissional. Mais detalhes sobre a formação e o desenvolvimento desse pólo moveleiro podem ser encontrados, por exemplo, em [St02], [LS04], [Ci04].

A pesquisa desenvolvida neste tema visa contribuir com a iniciativa de aumentar a produtividade e a qualidade da indústria moveleira. $\mathrm{Na}$ próxima seção descrevemos o processo de produção de móveis de madeira a partir de observações feitas em uma fábrica de pequeno porte característica do Pólo de Votuporanga. Na Seção 3 discutimos o problema de corte de estoque bidimensional no contexto da indústria de móveis. Na Seção 4 fazemos uma análise dos padrões de corte utilizados pela fábrica e propomos um algoritmo que sistematiza a construção desses padrões de corte. Um estudo computacional comparando o algoritmo proposto com o método em 2-estágios de Gilmore e Gomory contido no sistema CorteBi [CR04] e com dados fornecidos pela empresa é apresentado na Seção 5. Na Seção 6 são feitas as considerações finais.

\section{Uma empresa característica}

Os processos de produção de móveis de madeira nas pequenas e médias empresas situadas em Votuporanga são similares. $O$ foco deste trabalho é em empresas que produzem móveis retilíneos [St02], e que usam como matéria prima principal madeira aglomerada (Aglomerado, Compensado, MDF (Medium-Density Fiberboard), OSB (Oriented Strand Board)). A linha de produção descrita a seguir é baseada nas informações colhidas em uma empresa característica do setor, Fábrica V, situada em Votuporanga-SP. As principais diferenças entre o processo produtivo da Fábrica $V$ e de outras empresas visitadas estão em estágios específicos de algum produto ou na modernidade de certos equipamentos [CR04].

A confecção de um móvel envolve diversas etapas e equipamentos. No início da semana, o gerente de produção decide quais os móveis e o tamanho dos lotes que serão produzidos durante a semana. A linha de produção é então totalmente dedicada à produção desses móveis. Inicialmente, a matéria prima principal, painéis retangulares de madeira de diversas espessuras, passa pelo setor de corte (primário e secundário). O setor de corte primário possui uma máquina seccionadora na qual os painéis retangulares (objetos) são cortados em retângulos menores (itens) que irão compor o móvel. Se necessário, os itens são enviados para o setor de corte secundário. No setor de corte secundário existem máquinas de corte menores que podem ser utilizadas no aparo das perdas, e no corte de itens que foram agrupados. Os itens são então encaminhados para o setor de usinagem, que é responsável pelos processos que darão outros tipos de formatos (não-retangulares) aos itens por meio de serras e ferramentas específicas, de acordo com o design do produto. Nesta etapa são realizadas também operações de furações, frezza (acabamento para tirar as irregularidades provenientes da usinagem), e a colagem ou colocação de bordas. Após estas operações, alguns itens são agrupados e encaminhados para o setor de montagem. Nesse setor, algumas peças são pré-montadas e preparadas para a pintura. $\mathrm{O}$ setor de pintura é formado por um conjunto de máquinas que operam interligadas. Antes de ser usado, esse conjunto de máquinas necessita de um preparo que envolve sua limpeza e a carga das tintas. Depois da pintura, os itens e as peças pré-montadas são enviados para a colocação de acessórios

Pesquisa Operacional, v.28, n.3, p.451-472, Setembro a Dezembro de 2008 
(e.g. puxadores de portas e gavetas, fechaduras), agrupados e armazenados em caixas específicas (alguns produtos são armazenados montados). Um esquema da linha de produção é apresentado na Figura 1.

$\mathrm{Na}$ empresa, o espaço para armazenamento dos móveis embalados, ou mesmo para itens que foram cortados e que não serão usados nas demais etapas do processo no mesmo dia do corte, é limitado. Portanto, há interesse da empresa em cortar apenas os itens que compõem o móvel cuja produção iniciou-se no dia do corte.

Uma prática observada entre as empresas de pequeno e médio portes da região é a elaboração do design do produto e de padrões para o corte dos objetos (padrões de corte) simultaneamente. Em geral, os padrões de corte para obtenção dos itens necessários para a fabricação de um determinado produto são elaborados manualmente. Se necessário, as dimensões do produto são modificadas para permitir um melhor aproveitamento do objeto. A capacidade da seccionadora de cortar vários objetos ao mesmo tempo também é considerada na elaboração do padrão de corte. Uma vez concluído o design do produto, os padrões de corte associados são armazenados e serão utilizados posteriormente no processo de produção do mesmo. No entanto, é comum acontecer que, ao iniciar o processo de produção, os objetos disponíveis em estoque para o corte dos itens que compõem um determinado móvel possuem dimensões diferentes do objeto para o qual os padrões de corte foram elaborados. Este fato cria diversas dificuldades operacionais, e a falta de um sistema computacional para a elaboração dos padrões diminui a capacidade produtiva, e pode dificultar o bom aproveitamento da matéria prima.

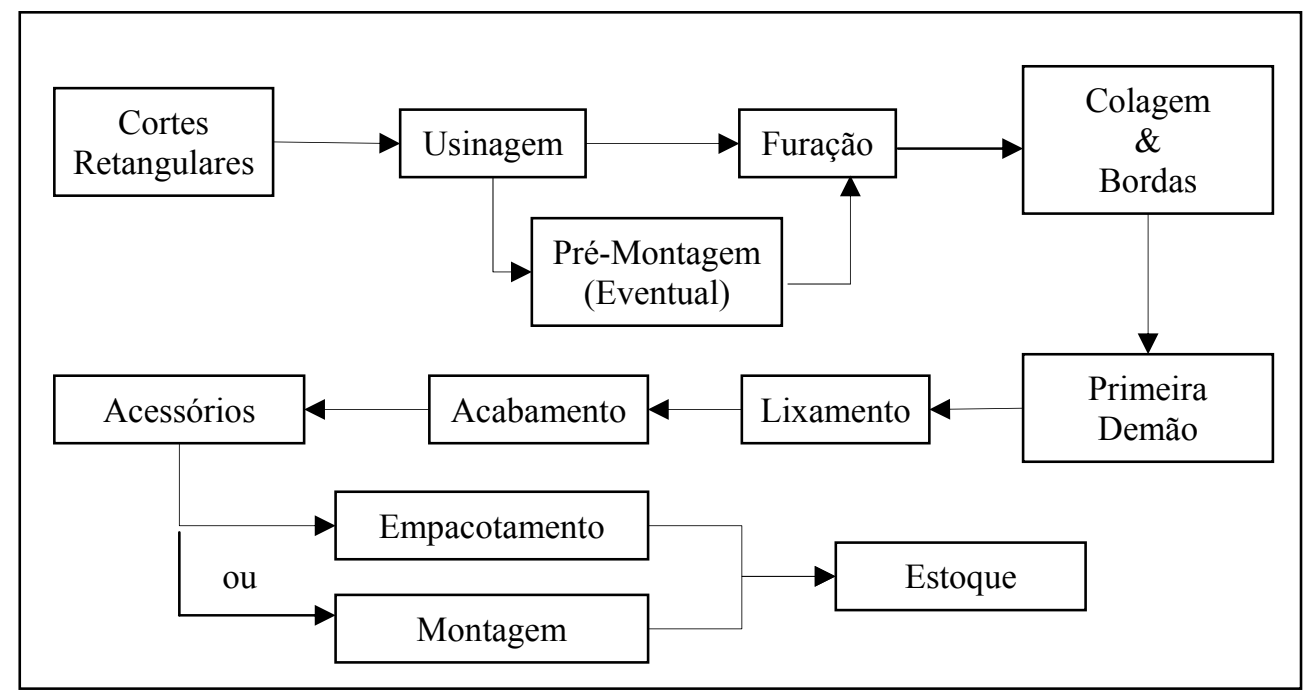

Figura 1 - Esquema da linha de produção em uma fábrica de móveis [Ca04].

Uma preocupação importante, na maioria das empresas do setor, é com o bom aproveitamento da matéria prima e utilização eficiente da máquina seccionadora. Existe um grande interesse das empresas pela elaboração de padrões de corte que permitam uma rápida manipulação e um bom aproveitamento dos painéis de madeira. Qualquer parte do objeto que não é aproveitada na produção do móvel em questão é considerada perda de matéria prima. 
Dado o alto custo da matéria prima (painéis de MDF) a minimização da perda do objeto é o principal critério usado na avaliação da qualidade de um padrão de corte.

Diversos aspectos do sistema de produção das indústrias de móveis de pequeno e médio portes são de grande interesse e relevantes para aumento da qualidade. A definição do tamanho do lote, o sequenciamento da produção, e a elaboração de padrões de corte são alguns desses aspectos. Nas próximas seções abordamos o problema de elaborar padrões de corte eficientes, isto é padrões de corte que minimizem a perda de matéria prima e tenham um baixo custo operacional.

\section{O Problema de Corte de Estoque Bidimensional}

O problema de cortar painéis retangulares de madeira (objetos) mantidos em estoque em retângulos menores (itens) de acordo com uma demanda pré-especificada, é conhecido como O problema do corte de estoque bidimensional.

A ferramenta principal usada para resolver o problema de corte de estoque é baseada no método simplex com geração de colunas [Ch83] e foi proposta por Gilmore \& Gomory ([GG61], [GG63], [GG65]) para resolver os casos uni e bidimensional. Na discussão que segue, vamos considerar que existe em estoque uma quantidade suficiente de objetos retangulares de comprimento $L$ e largura $W$ para produzir um conjunto de $m$ itens retangulares menores de comprimento $l_{i}$, largura $w_{i}$ e demanda $d_{i}$. Considerando o plano cartesiano, o comprimento do objeto é tomado relativo ao eixo horizontal e a largura relativa ao eixo vertical.

Suponha inicialmente que são conhecidos todos os padrões de corte viáveis. Seja $n$ o número total de padrões de corte, e $A_{j}, j=1 \ldots n$, um vetor $m$-dimensional tal que cada elemento $a_{i j}$ representa o número de itens do tipo $i$ no padrão de corte $j$. Considerando o critério de minimização do custo total, o problema de corte de estoque bidimensional pode ser modelado como:

$$
\begin{aligned}
& \operatorname{minimizar} \sum_{j=1}^{n} c_{j} \cdot x_{j} \\
& \text { s.a: } \sum_{j=1}^{n} a_{i j} \cdot x_{j}=d_{i} \quad i=1 \ldots m \\
& x_{j} \in Z^{+}, \quad j=1 \ldots n
\end{aligned}
$$

onde a variável de decisão $x_{j}$ representa o número de objetos cortados de acordo com o padrão de corte $j$.

O custo $c_{j}(j=1 \ldots n)$ atribuído a cada padrão de corte pode representar, por exemplo, o preço segundo o fornecedor ou a perda em cada padrão de corte. Neste último caso, o custo associado a cada padrão de corte $j$ pode ser calculado como:

$$
c_{j}=L \cdot W-\sum_{i=1}^{m}\left(a_{i j} \cdot \ell_{i} \cdot w_{i}\right), \quad j=1 \ldots n .
$$

O conjunto de restrições (2) garante que a demanda será atendida exatamente e as restrições (3) indicam o tipo das variáveis. Note que quando a demanda é atendida exatamente, minimizar o número de objetos cortados é equivalente a minimizar a perda total [AMY04]. $\mathrm{Na}$ resolução do problema de corte de estoque discutido a seguir, e nas demais seções do texto, consideramos como critério de otimização a minimização do número de objetos cortados, isto é: $c_{j}=1, j=1 \ldots n$. 
O problema de corte de estoque também pode ser resolvido considerando a produção de itens em excesso, ou mesmo dentro de um determinado intervalo (demanda flexível). Nestes casos o conjunto de restrições (2) deve ser modificado para:

$$
\sum_{j=1}^{n} a_{i j} \cdot x_{j} \geq d_{i} \quad i=1 \ldots m
$$

ou

$$
d_{i}^{\prime} \leq \sum_{j=1}^{n} a_{i j} \cdot x_{j} \leq d_{i} \quad i=1 \ldots m
$$

respectivamente. Na resolução do problema de corte de estoque na indústria de móveis consideramos dois casos: o atendimento exato da demanda e a produção de itens em excesso. $\mathrm{O}$ caso em que a demanda é flexível pode ser tratado usando uma função objetivo fracionária como critério de otimização, conforme proposto por Gilmore \& Gomory [GG63] para o problema de corte de estoque unidimensional. Carniere \& Mendoza [CM00] utilizam esta estratégia para resolver o problema de corte de estoque bidimensional.

Na maioria das situações práticas, o número de padrões de corte é muito alto o que difículta a obtenção da solução ótima do problema (1)-(3). Relaxando as restrições (3) para $x_{j} \in R^{+}$é possível resolver o problema de otimização linear contínua resultante pelo método simplex com geração de colunas. Inicialmente são gerados $m$ padrões de corte para compor a matriz básica inicial. A cada iteração do método simplex é resolvido um subproblema de otimização para gerar um novo padrão de corte que poderá ou não substituir um dos $m$ padrões contidos na matriz básica corrente. Isto é, a cada iteração o subproblema (GC) dever ser resolvido:

$$
C G: \max \left\{\pi y: y \in\left\{A_{1} \ldots A_{N}\right\},\left(A_{j}, \mathrm{j}=1 \ldots \mathrm{n} \text { é um padrão de corte bidimensional }\right)\right\}
$$

onde $\pi$ é o vetor de variáveis duais associadas às restrições de demanda (2). Em situações onde a demanda é alta, a solução inteira pode ser obtida pelo arredondamento da solução contínua [e.g. GG61, MA00]. No caso mais geral, soluções inteiras podem ser obtidas por heurísticas de arredondamento (e.g [PA06, CMWX08]) ou pelo método branch and price (e.g. [Va98], [BS06]).

O método simplex com geração de colunas tem sido usado para resolver problemas de corte de estoque em diversos tipos de indústria (e.g. papel, metal, móveis). O que difere uma aplicação de outra é o subproblema (GC) associado. Diversas restrições relativas às dimensões do objeto e dos itens, ao tipo de equipamento de corte, entre outros fatores, devem ser consideradas na geração dos padrões de corte. No caso da indústria de móveis, (GC) é um problema de corte bidimensional onde apenas um objeto esta disponível (problema 2/B/O, de acordo com a classificação proposta por Dyckhoff [Dy90]).

A Fábrica V produz móveis usando painéis de madeira de diversas espessuras. Para obter todos os itens que compõem um determinado produto resolve-se um problema de corte de estoque bidimensional para cada uma das espessuras necessárias. Neste trabalho consideramos que existe um único tipo de objeto, isto é apenas uma dimensão $(L \times W)$, de acordo com a prática da empresa que procura manter em estoque apenas um tipo de objeto de cada espessura. A solução do problema considerando vários tipos de objetos pode ser obtida resolvendo em cada iteração do método simplex um problema (GC) para cada tipo de objeto (e.g. [Ci06, MA00, CMWX08]). Na próxima seção discutimos o problema GC no contexto da indústria de móveis. 


\section{Heurística para a Geração de Padrões Tabuleiros Compostos}

Diversos fatores devem ser considerados na elaboração de padrões de corte. Por limitação operacional da maioria dos equipamentos de corte encontrados nas indústrias de móveis, um padrão de corte é viável se for guilhotinado. Um corte feito de uma extremidade a outra de um retângulo, dividindo o objeto em retângulos menores é denominado corte guilhotinado ortogonal, ou simplesmente corte guilhotinado [AMY04].

O número de estágios de corte é outro fator importante a ser considerado na geração de um padrão de corte. Cada vez que a direção do corte muda, isto é o objeto é rotacionado em $90^{\circ}$, temos novo estágio de corte. Se ao término do último estágio, todos os itens tiverem sido obtidos, o padrão de corte é dito exato, se for necessário um corte adicional (apara) o padrão é não-exato. Normalmente as aparas são feitas em outros equipamentos de corte (na Fábrica V as aparas são feitas setor de corte secundário), e portanto são desconsideradas na contagem do número de estágios. A Figura 2 ilustra um padrão de corte guilhotinado exato em três estágios. As linhas pontilhadas indicam a direção do corte.
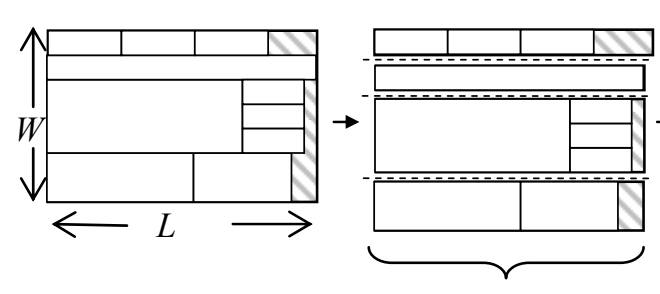

$1^{\circ}$ Estágio

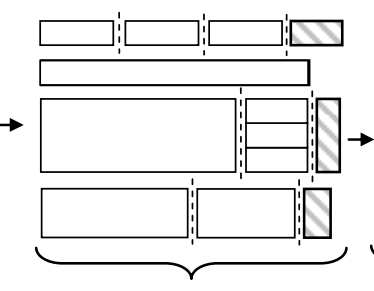

$2^{\circ}$ Estágio

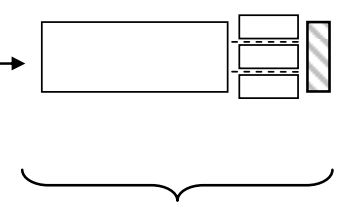

$3^{\circ}$ Estágio

Figura 2 - Etapas do corte de um objeto de acordo com um padrão de corte 3-estágios.

Alguns equipamentos de corte possuem restrições quanto ao número máximo de estágios permitidos (e.g. [MG98]). Além disso, cada vez que o objeto é rotacionado, o tempo de produção é penalizado. Assim, o número de estágios de um padrão de corte é fator importante a ser considerado, não apenas para determinar a viabilidade de um padrão, mas também a sua qualidade considerando o tempo necessário para realizar as operações de corte. Outras restrições associadas ao equipamento de corte são discutidas, por exemplo, em [MB06].

Se existem restrições quanto ao número de itens de cada tipo contidos no padrão de corte, dizemos que o padrão de corte é restrito. Um padrão de corte é dito homogêneo se contém apenas um tipo de item. Um padrão homogêneo é maximal se contém o maior número possível de itens de um único tipo [Ci06].

\section{Padrões de Corte 2-estágios}

Gilmore \& Gomory [GG65] propuseram um método para gerar padrões de corte guilhotinados em dois estágios (isto é apenas um subconjunto de padrões de corte viáveis para o problema GC é gerado). Primeiro, o objeto é dividido em um conjunto de faixas. Cada faixa é então dividida ao longo do comprimento. Supondo que o conjunto de itens esteja ordenado de forma que $w_{i} \leq w_{i+1}, i=1 \ldots m-1$, o método pode ser descrito pelo Algoritmo GC2-estágios descrito no Quadro 1. 


\section{Algoritmo GC2-estágios}

Passo 1 - (Construção das faixas) Para cada largura $w_{i}, i=1 \ldots m$ resolva 0 seguinte problema da mochila:

$$
G M_{i}: \pi_{i}^{*}=\max \left\{\sum_{k=1}^{i} \pi_{k} r_{i k}: \sum_{k=1}^{i} l_{i} r_{i k} \leq L, r_{i k} \in Z^{+}\right\}
$$

Passo 2 - (Montagem do padrão) Resolva o seguinte problema da mochila:

$$
\max \left\{\sum_{k=1}^{m} \pi_{k}^{*} z_{k}: \sum_{k=1}^{m} w_{k} z_{k} \leq W, z_{k} \in Z^{+}\right\}
$$

Passo 3 - (Recuperação do padrão) A coluna associada ao padrão de corte obtido nos Passos 1 e $2, A_{j}$, é dada por:

$$
a_{i j}=\sum_{k=1}^{m} z_{k} r_{i k}
$$

Quadro 1 - Algoritmo GC2-estágios.

Para a obtenção de um padrão de corte pelo Algoritmo GC2-estágios, é necessário resolver $(m+1)$ problemas da mochila inteiros. Usando programação dinâmica, é possível resolver os $m$ problemas da mochila associados ao Passo 1 simultaneamente. Note que podem ser gerados padrões de corte 2-estágios não-exatos caso os itens contidos em uma faixa tenham largura diferente da largura da faixa. Se mais de um item possui a mesma largura, o número de problemas da mochila a ser resolvido no Passo 1 pode ser reduzido.

O tempo de preparo do equipamento de corte também deve ser observado na geração de padrões de corte que facilitem a operação de corte. Na Fábrica V, o ajuste dos batentes de fixação do objeto na máquina seccionadora é manual (ver seção 2). Para cada largura de faixa distinta do primeiro estágio, é necessário um novo ajuste dos batentes para determinar a largura a ser cortada. Além disso, é necessário ajustar um segundo conjunto de batentes para o corte dos itens nas faixas. O tempo total necessário para o ajuste, de $50 \mathrm{~s}$ a $2 \mathrm{~min}$, é considerado alto quando comparado à velocidade de corte da seccionadora (aproximadamente $14 \mathrm{~m}$ por minuto). Assim, é desejável usar padrões de corte com poucas faixas de larguras diferentes e poucos itens de comprimentos diferentes. Mais detalhes sobre a máquina seccionadora usada na Fábrica V podem ser obtidos em [Fi06] e [Mo07].

A Fábrica $\mathrm{V}$ busca determinar padrões de corte com índices de perda e custo operacional baixos. A fábrica considera aceitável padrões com perda abaixo de $6 \%$ da área total do objeto. Em Cavali \& Rangel [CR04] o sistema CorteBi ([PR89], [RL07]), que gera padrões de corte em 2-estágios de acordo com o Algoritmo GC2-estágios, foi usado para resolver o problema de corte de estoque da Fábrica V. O CorteBi se mostrou útil como sistema de apoio à tomada de decisões devido ao tempo de resposta e qualidade da solução. $O$ sistema resolveu problemas com até 20 itens em menos que dois segundos e gerou padrões de corte com índice de perda entre $3,07 \%$ e 5,27\% considerando a rotação dos itens. A Figura 3 mostra dois padrões de corte gerados pelo sistema CorteBi. 


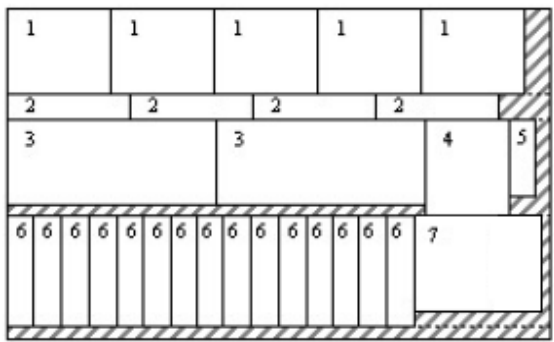

a) Padrão Rejeitado (perda 4.19\%)

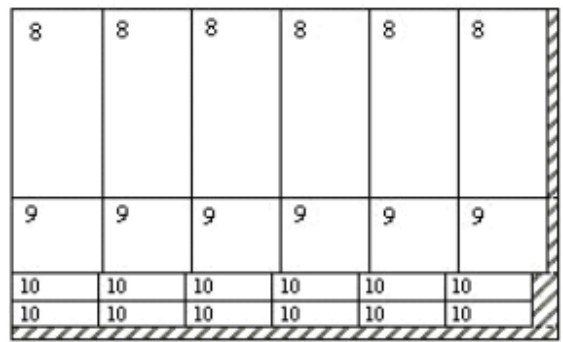

b) Padrão aceito (perda 2.73\%)

Figura 3 - Padrões de corte gerados pelo sistema CorteBi.

Os dois padrões de corte mostrados na Figura 3 possuem perda aceitável pela Fábrica V $(4,19 \%$ e $2,73 \%)$, mas o padrão de corte a), apesar de ter um índice de perda menor que $6 \%$, foi rejeitado pela fábrica por causa da dificuldade no processo de corte. Esse padrão contém quatro faixas de larguras distintas e sete itens de comprimentos distintos. O padrão de corte b) foi aceito. Apesar de possuir três faixas de comprimentos distintos, o padrão de corte b) possui dois conjuntos de faixas que podem ser cortadas simultaneamente no segundo estágio, característica de um padrão de corte 2-grupos.

\section{Padrões de Corte $\boldsymbol{n}$-grupo}

Um padrão n-grupo, estudado por Gilmore \& Gomory [GG65] em aplicações na indústria de vidro e metal, é um padrão de corte guilhotinado em 2-estágios no qual as faixas resultantes do primeiro estágio são divididas em grupos de forma que cada grupo de faixas é cortado simultaneamente no segundo estágio. Se o padrão contiver apenas um grupo de faixas temos um padrão tabuleiro ou 1-grupo [KY04]. Uma característica destes padrões é que todos os itens apresentam-se distribuídos em linhas e colunas, num formato que nos faz lembrar um tabuleiro de xadrez ou dama (ver Figura 4). Os padrões tabuleiros necessitam de pouco manuseio do objeto e, portanto, possuem um baixo custo operacional ([MA00], [KY04]), porém podem apresentar altos índices de perda. Tal como os demais, um padrão de corte n-estágios pode ser exato ou não-exato, conforme a necessidade ou não de apara.

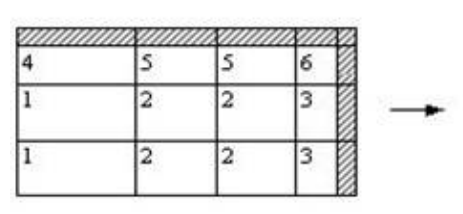

$1^{\mathrm{o}}$ estágio
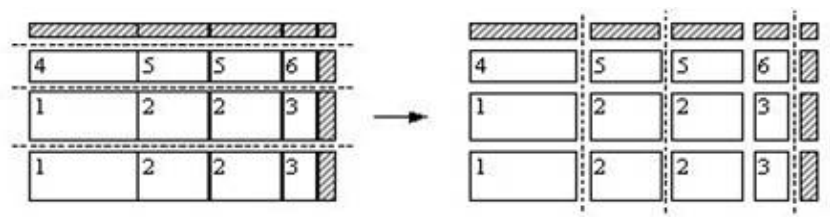

$2^{\circ}$ estágio

Figura 4 - Processo de corte de Padrão Tabuleiro Exato.

Alguns trabalhos na literatura apresentam modelos matemáticos para a geração de padrões $n$-grupos. Morabito \& Arenales [MA00] apresentam um modelo de otimização não linear para a geração de padrões tabuleiros e um procedimento heurístico adaptado do procedimento em dois estágios de Gilmore \& Gomory [GG65] para resolver o problema. 
Katsurayama \& Yanasse ([KY05], [KY06]) propõem procedimentos baseados na enumeração implícita dos itens a serem incluídos no padrão para a geração de padrões tabuleiros exatos e restritos. Yanasse \& Morabito ([YM06a], [YM06b]) apresentam e avaliam computacionalmente diversos modelos de otimização linear e não-linear para geração de padrões tabuleiros, padrões 2-grupos e padrões 3-grupos.

Os padrões $n$-grupo podem ser identificados entre os padrões usados na indústria de móveis. A Figura 5 mostra um padrão de corte usado na Fábrica V. Se o padrão de corte mostrado em a) for orientado da esquerda para a direita e de cima para baixo, veremos no canto superior esquerdo um bloco principal que é um padrão tabuleiro (subpadrão Tabuleiro b)).

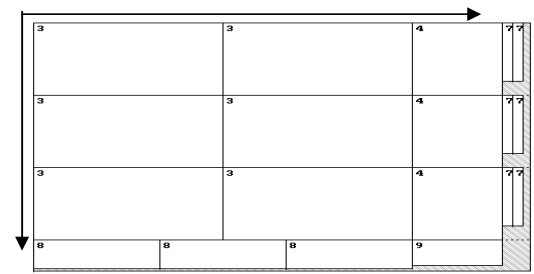

a) Padrão de corte

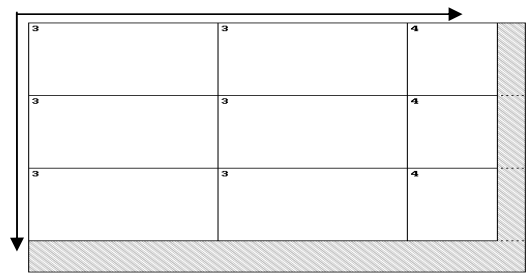

b) Subpadrão Tabuleiro

Figura 5 - Padrão de Corte usado na Fábrica V.

Neste caso dizemos que o padrão da Fábrica $\mathrm{V}$ foi obtido a partir de um padrão tabuleiro. As áreas não utilizadas do padrão tabuleiro foram reaproveitadas, tratadas como novos objetos, e novos padrões tabuleiro foram gerados para área ociosa, mantendo o padrão final em 2-estágios. Isto é, o padrão da Fábrica V é um padrão em 2-estágios resultante da composição de padrões tabuleiros, ou seja, um padrão tabuleiro composto.

Os padrões utilizados pela Fábrica $\mathrm{V}$ apresentam bons resultados operacionais com índices de perdas aceitáveis. A heurística descrita a seguir, Heurística TC, foi desenvolvida explorando a idéia de compor padrões tabuleiros para resolver o problema de corte de estoque considerando padrões de corte similares aos usados pela fábrica. O ponto de partida do método é a construção de padrões tabuleiro (Figura 6a). Algumas faixas destes padrões são removidas (padrão derivado - Figura 6b). As áreas ociosas nestes padrões (áreas A e B na Figura 6) são consideradas novos objetos, e se possível, ocupadas por outros itens.

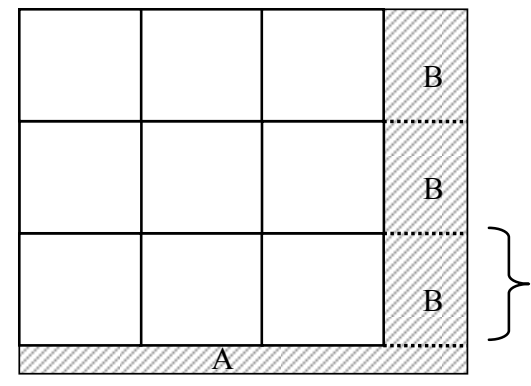

a) Padrão Tabuleiro

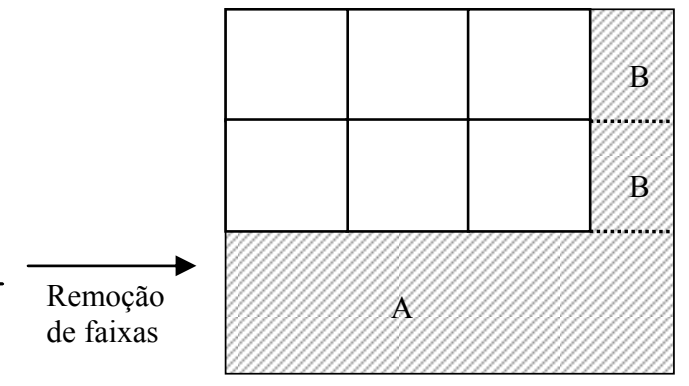

b) Padrão derivado

Figura 6 - Padrão de corte derivado e áreas ociosas. 
A Heurística TC é realizada em três etapas. Na Etapa 1 são construídas faixas pela combinação de itens ao longo do comprimento do objeto. Na Etapa 2 as faixas são combinadas ao longo da largura do objeto formando padrões tabuleiros compostos. Esses padrões de corte são armazenados e usados na Etapa 3 para resolver o problema de corte de estoque. O procedimento é detalhado na Heurística TC (Quadro 2).

\section{Heurística TC}

Etapa 1 - Construção das faixas

Passo 1 - Leia os dados referentes a dimensão do objeto $(L, W)$ e dos itens, $\left(l_{i}, w_{i}\right)$, $i=1 \ldots m$, se desejado faça a rotação dos itens. Ordene os $m \leq p \leq 2 m$ itens de forma que $w_{i} \leq w_{i+1}, i=1 \ldots p$ ( $p$ é o número total de itens considerados. Após a rotação, os novos itens que não cabem no objeto não desconsiderados).

Passo 2 - Use o item $k$ (item pivô), $k=1 \ldots p$, para criar até duas faixas de largura $w_{k}$ : uma faixa homogênea maximal e se possível uma faixa heterogênea contendo uma vez o item pivô e itens $j$ com a mesma largura que o item pivô. A faixa heterogênia é obtida resolvendo um problema da mochila com o objetivo de maximizar a área total ocupada, considerando os itens $j$ tais que tais que $w_{j}=w_{k}$, e capacidade igual a $L-l_{k}$.

Passo 3 - Para cada uma das faixas criadas no Passo 2, inclua, se possível, mais itens na faixa (área B da Figura 6). Resolva um problema da mochila com o objetivo de maximizar a área total ocupada e considerando os itens $j$ tais que $w_{j} \leq w_{k}$, e capacidade igual ao comprimento da área B.

Etapa 2 - Geração do conjunto de padrões tabuleiros compostos

Passo 4 - Para cada faixa criada Etapa 1, gere um padrão tabuleiro usando $\left\lfloor W / w_{k}\right\rfloor$ faixas (isto é no máximo dois padrões para cada $w_{k}$ ).

Passo 5 - Para cada padrão tabuleiro criado no Passo 4 crie $K$ padrões de corte derivados removendo faixas do padrão. Se um padrão tabuleiro possuir $t$ faixas, podem ser construídos até $(t-1)$ padrões derivados. A área ociosa associada às faixas removidas será considerada um novo objeto (área A na Figura 6).

Passo 6 - A área livre em cada padrão de corte derivado obtido no Passo 5 é considerada um novo objeto de dimensões $\left(L, W^{A}\right)$ (área A da Figura 6). Um padrão tabuleiro é então gerado para este objeto resolvendo o seguinte problema de otimização inteira:

$$
\begin{aligned}
\max & \sum_{\mathrm{i}=1}^{2 p} v_{i} \cdot r_{i} \\
\text { s.a: } & \sum_{\mathrm{i}=1}^{2 p} w_{i} \cdot r_{i} \leq W^{A} \\
& r_{i} \leq M y_{i}, \quad i=1 \ldots 2 p \\
& \sum_{i=1}^{2 p} y_{i} \leq 1 \\
& r_{i} \in Z^{+}, \quad y_{i} \in\{0,1\} \quad i=1 \ldots 2 p
\end{aligned}
$$


onde $r_{i}$ é o número de vezes que a faixa de largura de $w_{i}$ é usada no padrão, $y_{i}=1$ se a faixa $i$ é usada e zero caso contrário, $v_{i}$ é igual à área utilizada da faixa $i$. O conjunto de restrições (13) e a restrição (14) garantem a geração de um padrão tabuleiro, isto é apenas um grupo de faixas é usado no padrão.

Etapa 3 - Solução do problema de corte de estoque bidimensional usando padrões tabuleiros compostos

Passo 7 - Resolva o problema do corte de estoque bidimensional (1)-(3) considerando o conjunto de padrões de corte gerados na Etapa 2. Este conjunto irá conter até $2 p(K+1)$ padrões de corte diferentes. Isto é, a matriz $A$ na restrição de atendimento a demanda (restrição (2)) contém apenas padrões tabuleiros compostos.

Quadro 2 - Heurística TC - Gera padrões tabuleiros compostos e resolve o PCE.

A utilização da Heurística TC para resolver o problema de corte de estoque bidimensional garante o atendimento da demanda utilizando apenas padrões tabuleiros compostos. Note que a restrição (14) do problema de otimização resolvido no Passo 6 permite apenas a geração de padrões 2-grupos. O relaxamento desta restrição considerando outros valores para o lado direito da inequação permite a geração de padrões $n$-grupos, $n>2$.

A qualidade dos padrões gerados pela Heurística TC depende do procedimento usado na geração do padrão tabuleiro nos Passos 4 e 6 . Os procedimentos adotados são heurísticos e não há garantias da qualidade da solução obtida. Padrões Tabuleiros com maior índice de aproveitamento do objeto, porém com um custo computacional maior, podem ser gerados usando, por exemplo, o algoritmo enumerativo de Katsurayama \& Yanasse ([KY06], [KY05]), ou resolvendo diretamente os modelos matemáticos discutidos em Yanasse \& Morabito ([YM06a], [YM06b]). Em Figueiredo \& Rangel [FR06] a Heurística TC foi testada usando o modelo proposto por Scheithauer (conforme descrito em [YM06b]) para gerar padrões tabuleiros no Passo 6. No entanto, os resultados obtidos não foram satisfatórios devido ao alto tempo computacional necessário para a resolução do modelo.

\section{Resultados Computacionais}

Os móveis produzidos na Fábrica $\mathrm{V}$ são fabricados com itens de diferentes espessuras (por exemplo 3, 9, 15, 18, 20 e $25 \mathrm{~mm}$ ). Assim, para obter todos os itens necessários para compor um determinado móvel, é necessário resolver um problema de corte de estoque para cada espessura de objeto. Todos os objetos têm dimensão (2750 x 1830) exceto o objeto de $15 \mathrm{~mm}$ cujas dimensões são $(2750 \times 1850)$. Nesta seção são apresentados resultados dos problemas de corte de estoque necessários para a fabricação de três produtos (P1, P2 e P3). O produto P1 é fabricado com itens de três espessuras diferentes $(3,12$ e $15 \mathrm{~mm})$, o produto P2 com itens de quatro espessuras diferentes (3, 9, 12 e $15 \mathrm{~mm})$ e o produto P3 com itens de seis espessuras diferentes $(3,9,12,15,20$ e 25$)$, um total de treze exemplares. O problema de corte de estoque bidimensional associado a cada espessura de objeto foi resolvido considerando a produção de itens em excesso, e o critério de otimização usado foi minimização do número total de objetos. Isto é, foi resolvido o seguinte problema: 


$$
\begin{gathered}
\operatorname{minimizar} \sum_{j=1}^{n} x_{j} \\
\text { s.a: } \sum_{j=1}^{n} a_{i j} \cdot x_{j} \geq d_{i} \quad i=1 \ldots m \\
\quad x_{j} \in Z^{+}, j=1 \ldots n .
\end{gathered}
$$

As características principais dos conjuntos de itens utilizados nos testes estão descritas na Tabela 1. Os conjuntos foram nomeados de acordo com o produto e a espessura do objeto, assim P1-15 quer dizer conjunto de itens de $15 \mathrm{~mm}$ de espessura necessários para a produção de P1, e P2-20 é o conjunto de itens de $20 \mathrm{~mm}$ de espessura necessários para a produção de P2. Nesta tabela são descritos, para cada conjunto de dados, o número de itens $(\mathrm{m})$, as dimensões e demanda de cada item $\left(l_{i}, w_{i}, d_{i}\right)$, e o valor da demanda total $(T d)$. Alguns itens na tabela têm demanda nula $\left(d_{i}=0\right)$. Estes itens são facilmente aproveitados pela Fábrica V para a produção de um item chamado pinázio e são incluídos no conjunto, mesmo não sendo necessários para a confecção de um determinado produto, para possibilitar um melhor aproveitamento do objeto. Assim, reproduzimos no estudo computacional uma prática adotada pela fábrica. Os dados usados neste estudo foram gentilmente cedidos pela Fábrica V.

Tabela 1 - Características dos Conjuntos de itens.

\begin{tabular}{|c|c|c|}
\hline Nome & $\boldsymbol{m}$ & $\left(l_{i}, w_{i}, d_{i}\right)$ \\
\hline P1-03 & 3 & $(445,213,1200),(410,383,600),(388,377,900)$ \\
\hline P1-12 & 2 & $(390,110,1800),(370,110,900)$ \\
\hline P1-15 & 2 & $(600,440,600),(450,132,900)$ \\
\hline \hline P2-03 & 3 & $(710,535,320),(1062,530,320)(647,453,960)$ \\
\hline P2-09 & 3 & $(630,50,480),(433,50,320),(295,50,480)$ \\
\hline P2-12 & 6 & $\begin{array}{r}(440,65,320),(635,50,160),(454,180,960),(635,180,480),(454,135,640), \\
(635,135,320)\end{array}$ \\
\hline P2-15 & 7 & $(970,570,320),(700,75,160),(700,212,480),(700,163,320)$, \\
\hline P3-03 & 8 & $(600,400,0),(430,60,0),(500,60,0)$ \\
\hline P3-09 & 4 & $\begin{array}{r}(2500,565,240),(647,453,160),(710,454,80),(454,454,80),(1080, \\
454,200),(530,454,200),(1050,500,40),(483,215,80)\end{array}$ \\
\hline P3-12 & 3 & $(510,450,40),(630,50,0),(433,50,0),(295,50,0)$ \\
\hline P3-15 & 9 & $\begin{array}{r}(1049,452,200),(499,452,200),(452,429,80),(1050,535,80),(535,500,80), \\
(535,430,80),(700,212,160),(430,60,0),(500,60,0)\end{array}$ \\
\hline P3-20 & 9 & $\begin{array}{r}(454,180,320),(635,180,160),(454,135,0) \\
(1050,60,200),(430,60,120),(440,60,160),(1060,60,80)\end{array}$ \\
\hline P3-25 & 3 & $(430,60,80),(500,60,160),(1050,60,160)$ \\
\hline
\end{tabular}


Cada problema de corte de estoque foi resolvido usando duas estratégias diferentes, o sistema CorteBi [RL07] e a Heurística TC apresentada na Seção 4. A Heurística TC foi implementada usando o sistema XPRESS [Da04], os modelos de otimização foram escritos na sintaxe do Xpress-Mosel (problemas associados aos Passos 3, 6 e 7) e resolvidos pelo método branch and cut incluído no software Xpress-MP. O código da Heurística TC na sintaxe do Xpress-Mosel pode ser encontrado em [Fi06]. Todos os testes foram executados em um microcomputador AMD-Athlon 2200 com 256 MB RAM. Os tempos computacionais do CorteBi e da Heurística TC foram da ordem de segundos (médias de 16,8s e de 0,16s para a heurística TC e o CorteBi respectivamente, excluindo o tempo para o conjunto P3-20 O tempo computacional da heurística TC e do CorteBi associado ao P3-20 foi de 94,4s e 307,8 s respectivamente.) e, portanto não são apresentados em detalhes. Os resultados obtidos por estas duas estratégias foram comparados aos resultados da Fábrica V.

Um dos critérios usados na avaliação dos resultados obtidos é a perda da matéria prima. Para tanto, fazemos uma distinção entre a perda total e a perda por sobra de material em um padrão de corte. Em geral, os padrões de corte são avaliados de acordo com a perda total (calculada pela expressão (4)). No entanto, neste cálculo estão incluídas perdas inerentes ao processo de corte propriamente dito, chamadas de perdas por desgaste da serra. Uma outra parte que compõe a perda total é igual à soma das áreas dos itens cortados e não demandados, ou seja, retalhos quaisquer do objeto de dimensões não predefinidas, e é denominada perda por sobra de material ( $P S$ ). A perda devido ao desgaste da serra, em certos tipos de matéria prima (painéis de madeira, por exemplo), é inevitável e precisa ser levada em conta quando queremos avaliar o custo de produção. Porém, na avaliação da eficiência do padrão de corte, esta perda pode gerar uma distorção, pois padrões compostos por muitos itens pequenos irão sempre apresentar um alto percentual de perda devido ao desgaste da serra, sem que isso implique que sejam perdulários. O valor da perda por sobra de material pode ser estimado se incluirmos na fórmula do cálculo da perda total o desgaste devido à espessura da serra $(\delta)$ :

$$
P_{S}=\operatorname{Máximo}\left\{0 ; L \cdot W-\sum_{i=1}^{n}\left(a_{i} \cdot\left(\ell_{i}+\delta\right) \cdot\left(w_{i}+\delta\right)\right)\right\} .
$$

Note que neste cálculo não é considerado o desgaste da serra associado ao corte guilhotinado, mas apenas o desgaste da serra associado à individualização de cada item. Isto é, a perda por sobra calculada pela expressão (16) inclui uma parcela da perda associada ao desgaste da serra e, portanto, permite uma avaliação da qualidade do padrão de corte melhor do que a perda total. O desgaste da serra também foi considerado na geração dos padrões de corte, pois caso contrário, podem ser gerados padrões inviáveis [MA00].

Na Tabela 2 são apresentados os dados relativos à resolução dos problemas de corte de estoque pela Heurística TC, pelo sistema CorteBi e pela Fábrica V. Para cada conjunto de itens e método de solução são apresentados o número de Padrões (NP), o número de objetos (NO) e perda percentual por sobra de material (Sobra \%), valor máximo (Mx), médio (Md) e mínimo (Mn).

Podemos observar na Tabela 2 que a Heurística TC e o CorteBi apresentam, para a maioria dos problemas, índices de sobra médio abaixo do índice tolerado pela Fábrica V $(6 \%)$, apesar da Heurística TC gerar padrões com sobra de até 10,9\% (P1-03) e o CorteBi padrões que apresentam até $8,7 \%$ (P3-03). Note que nestes casos a Fábrica $V$ também gerou padrões com índice de perda acima de $6 \%$. Em relação à sobra média $(\mathrm{Md})$, o sistema CorteBi apresentou melhores resultados que a Heurística TC e que a Fábrica V para problemas associados ao 
produto P1. Para a P2 os resultados da Heurística TC são melhores ou iguais aos resultados do CorteBi e da Fábrica V. Para P3 a Heurística TC foi melhor em três dos seis problemas associados. É importante lembrar que os padrões gerados pelo sistema CorteBi e pela Fábrica V não são necessariamente padrões tabuleiros compostos. O CorteBi gera padrões de corte em 2-estágios gerais e alguns padrões de corte da Fábrica $V$ são padrões em três ou mais estágios. É interessante mencionar que o produto P3 é um dos mais vendidos pela fábrica e, portanto, tem recebido maior atenção no planejamento dos padrões de corte.

Tabela 2 - Aproveitamento de matéria prima: resultados Heurística TC, CorteBi e Fábrica V.

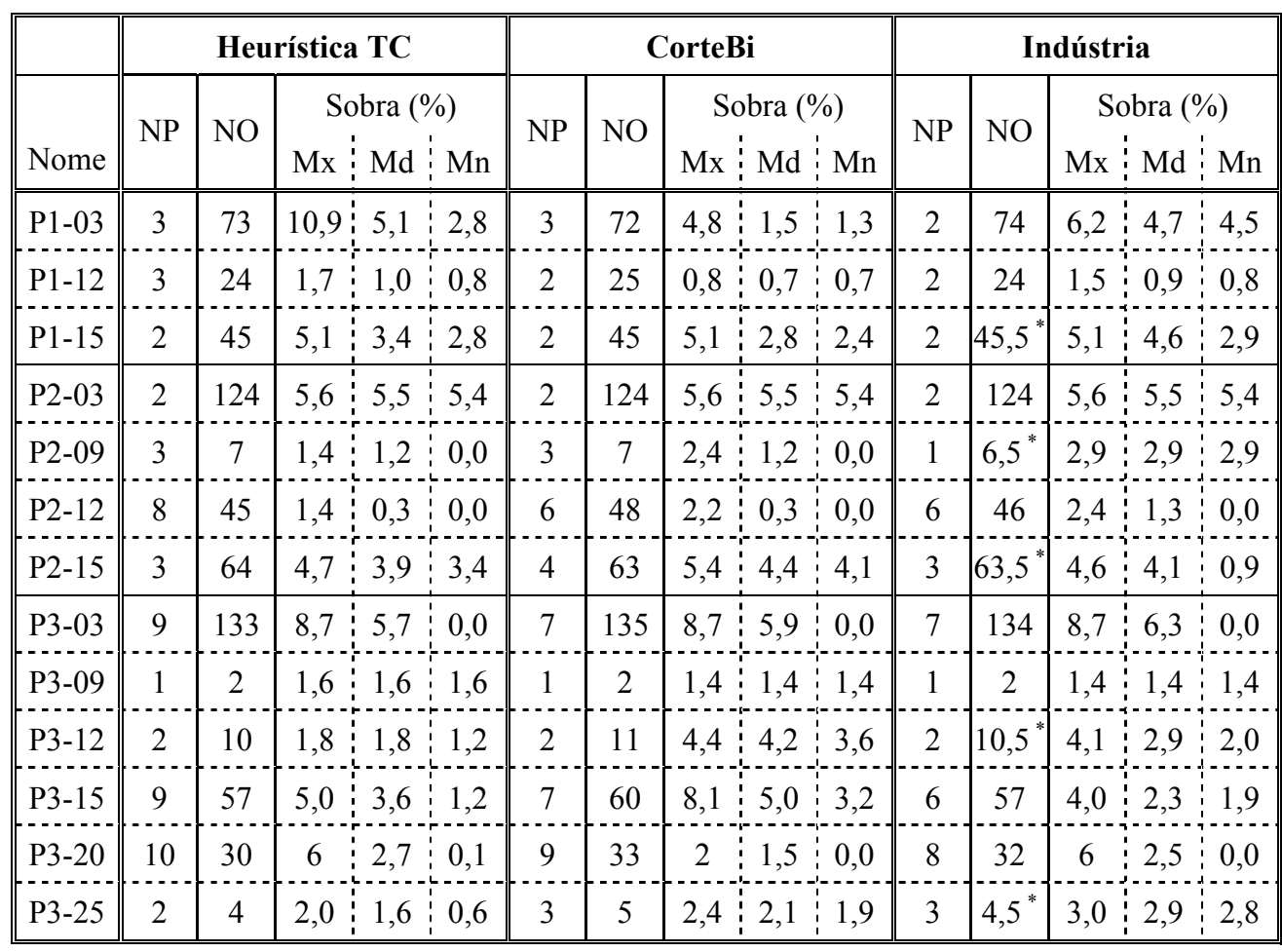

O número total de objetos necessários para atender a demanda é semelhante nos três procedimentos, com uma variação de no máximo três padrões, sendo que as soluções apresentadas pela Heurística TC envolvem um consumo menor de objetos. Por exemplo, a solução apresentada pela Heurística TC, pelo CorteBi e pela Fábrica V para o problema P2-12 usa 45, 48 e 46 objetos, respectivamente. É interessante observar a utilização de um número fracionário de objetos na solução da Fábrica $\mathrm{V}$ (resultados marcados com asterisco na Tabela 2). Para diminuir as perdas, a Fábrica V considera cortar um objeto utilizando o padrão de corte parcialmente, isto é a quantidade total de itens produzidos é menor que quantidade de itens previstos (ver Figura 7). Esta possibilidade não existe no sistema CorteBi ou na Heurística TC. A Fábrica V se refere a este padrão como " $1 / 2$ padrão de corte". Observe que usar " $1 / 2$ padrão de corte" não é equivalente a utilizar metade de um objeto. 


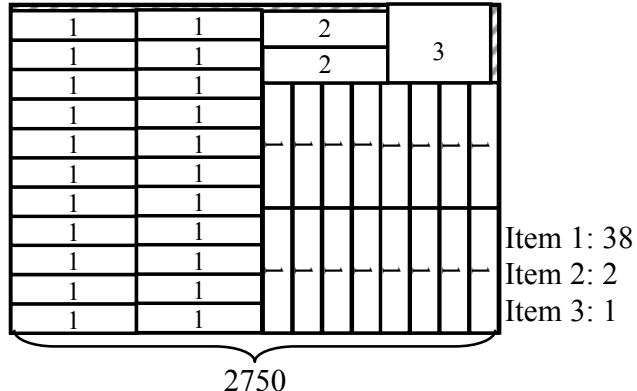

a) Padrão de corte (completo)

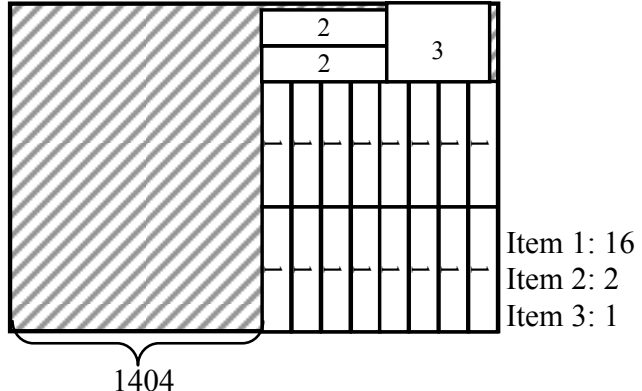

b) “ $1 / 2$ padrão de corte"

Figura 7 - Representação de "1/2 Padrão de corte".

A qualidade da solução apresentada pela Heurística TC pode ser mais bem observada se agruparmos os resultados considerando a produção total dos itens necessários para um determinado móvel (isto é, agruparmos a solução dos problemas de corte de estoque associados a cada espessura de objeto necessário para a produção do móvel). Na Tabela 3 é exibido, para cada produto, número total de padrões (NP), o número total de objetos (NO) e o percentual de perda por sobra de material (Sobra \%), calculado com base nos valores médios exibidos na Tabela 2. O sistema CorteBi apresenta os melhores resultados em termos de sobra média total apesar de ser melhor apenas para o produto P1. Em relação ao número total de objetos, a Heurística TC apresenta os melhores resultados. Na solução obtida com a Heurística TC, o consumo de objetos é menor que o do CorteBi (doze objetos) e que o da Fábrica V (5,5 objetos). No entanto, o número total de padrões de corte distintos necessários na solução da Heurística TC é bem superior que a solução do CorteBi e da Fábrica V, 6 e 12 objetos respectivamente.

Tabela 3 - Resumo do aproveitamento de matéria prima por produto.

\begin{tabular}{||c|c|c|c|c|c|c|c|c|c||}
\hline & \multicolumn{3}{|c|}{ Heurística TC } & \multicolumn{3}{c|}{ CorteBi } & \multicolumn{3}{c||}{ Fábrica V } \\
\hline Nome & NP & NO & $\begin{array}{c}\text { Sobra } \\
(\%)\end{array}$ & NP & NO & $\begin{array}{c}\text { Sobra } \\
(\%)\end{array}$ & NP & NO & $\begin{array}{c}\text { Sobra } \\
(\%)\end{array}$ \\
\hline P1 & 8 & 142 & $3,9 \%$ & 7 & 142 & $1,8 \%$ & 6 & 143,5 & $4,0 \%$ \\
\hdashline P2 & 16 & 240 & $4,0 \%$ & 15 & 242 & $4,1 \%$ & 12 & 240 & $4,2 \%$ \\
\hdashline P3 & 33 & 236 & $4,5 \%$ & 29 & 246 & $4,9 \%$ & 27 & 240 & $4,6 \%$ \\
\hline Total & 57 & 618 & $4,2 \%$ & 51 & 630 & $3,9 \%$ & 45 & 623,5 & $4,3 \%$ \\
\hline
\end{tabular}

$\mathrm{Na}$ avaliação da eficiência de um conjunto de padrões de corte é considerada também a produção dos itens em excesso. Na Tabela 4 são exibidos, para cada conjunto de dados (Nome), a demanda total de itens (Demanda), o número total de itens produzidos (Produção), e o excedente de produção (Excedente), valor nominal e percentual, obtidos na solução da Heurística TC, do CorteBi e da Fábrica V. Na análise apresentada, os pinázios foram excluídos por receberem um tratamento diferenciado na fábrica. O conjunto P3-25 só contém itens utilizados para a fabricação do pinázio e foi também desconsiderado. 
Tabela 4 - Resumo do Excedente de Produção.

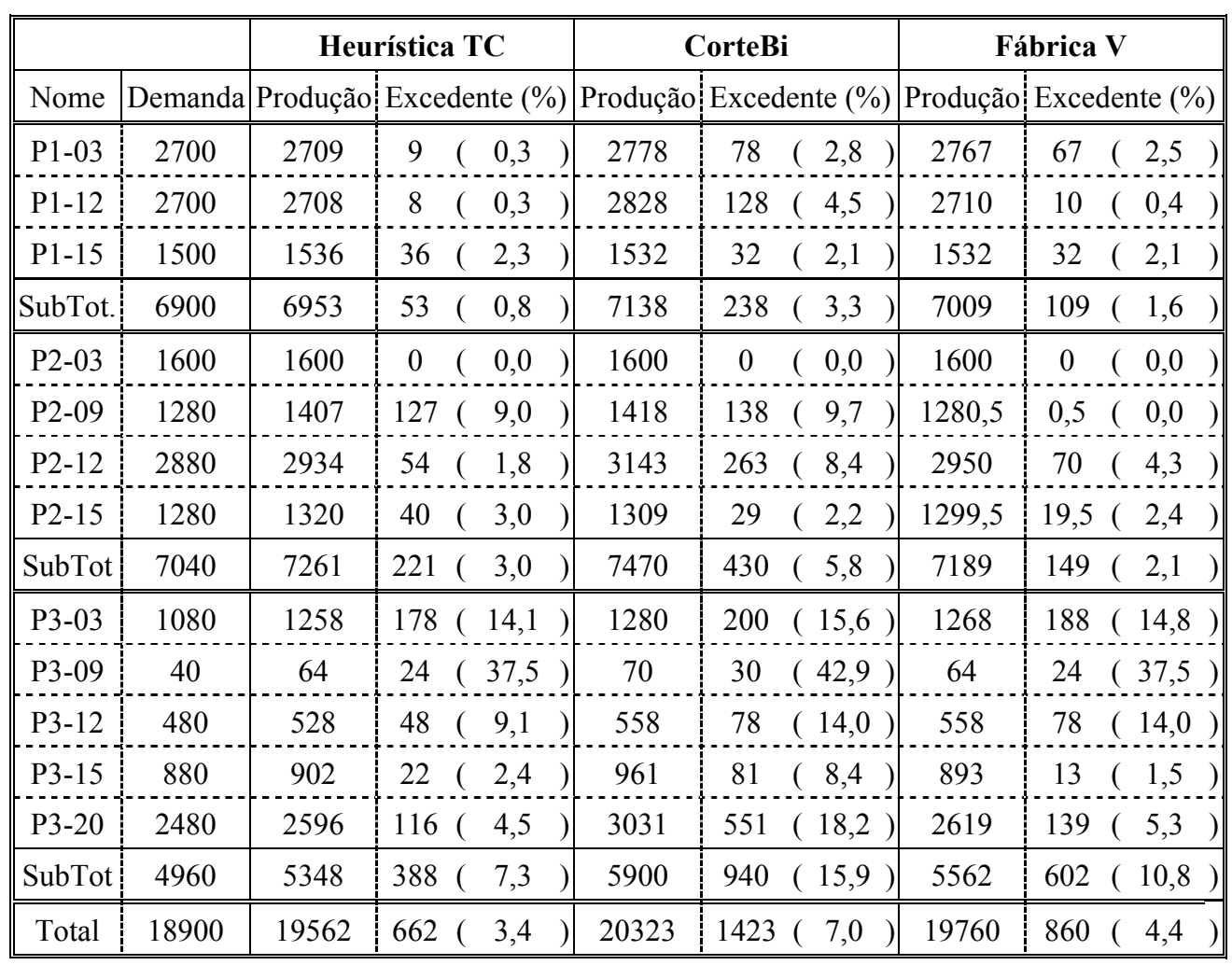

Para os produtos P1 e P3 a Heurística TC apresentou os menores valores percentuais totais de itens em excesso. A solução do CorteBi produz muitos itens em excesso por causa do procedimento de arredondamento da solução contínua obtida pelo método simplex com geração de colunas. A solução inteira é obtida fazendo para cada $x_{j} \in R, x_{j}=\left\lceil x_{j}\right\rceil$, $j=1 \ldots n$. O excedente de produção não implica necessariamente em perda. No entanto, a este excedente está atrelado um custo de armazenamento e um custo operacional, visto que, no caso de pequenas empresas, na falta de um espaço para criação de um estoque intermediário este excedente é armazenado na própria área de produção. A fábrica visitada procura evitar a produção de itens em excesso, pois, em geral, acarretam um aumento do custo de estoque e dificultam o controle da produção, conforme discutido na Seção 2. Mais detalhes sobre o estudo computacional realizado podem ser obtidos em [Fi06].

O número de padrões de corte nas soluções apresentadas pela Heurística TC é ligeiramente maior que o gerado pelos outros dois procedimentos (ver Tabelas 2 e 3). Um número alto de padrões de corte distintos implica em um número maior de ajustes na seccionadora. Além disso, pode ocorrer uma redução no número de objetos cortados simultaneamente de acordo com um determinado padrão, provocando a subutilização da máquina seccionadora em algumas operações de corte. A seqüência de ajustes da seccionadora para o corte de um ou mais objetos simultaneamente, limitada à sua capacidade de corte, é definida como ciclo da serra [YHZ93]. 
A máquina seccionadora utilizada na Fábrica $\mathrm{V}$ pode cortar objetos com até $60 \mathrm{~mm}$ de espessura. Esta capacidade de corte permite, por exemplo, o corte de quatro objetos de 15 $\mathrm{mm}$ ou 20 objetos de $3 \mathrm{~mm}$ simultaneamente. A fábrica procura trabalhar com o menor número possível de padrões de corte distintos para, com o agrupamento deles, reduzir o custo com o consumo de energia e o tempo de operação da máquina seccionadora. Um aspecto importante para aumentar a produtividade do processo de corte é minimizar o número de ciclos da serra. O desenvolvimento de procedimentos para geração de padrões de corte considerando também a minimização do número de ciclos da serra estão em andamento [MR06], [RM08].

\section{Conclusão e Perspectivas Futuras}

A pesquisa desenvolvida sobre o Problema de Corte de estoque na Indústria de Móveis tem proporcionado uma maior familiarização com o sistema produtivo deste setor e o desenvolvimento de algoritmos que podem ser úteis em sistemas de apoio à tomada de decisões. $\mathrm{O}$ entendimento do processo de corte da matéria prima e a análise dos padrões de corte adotada por uma empresa característica do setor, permitiram identificar um tipo especial de padrão de corte que nomeamos de padrão tabuleiro composto. Os padrões tabuleiros compostos, que pertencem à classe dos padrões $n$-grupos, exibem as facilidades de corte dos padrões tabuleiros, porém com um melhor aproveitamento do objeto. A Heurística TC, descrita na Seção 4, para a geração de padrões tabuleiros compostos forneceu resultados que, de uma forma geral, se mostraram melhores que os praticados pela fábrica estudada. No entanto, a capacidade da seccionadora de cortar simultaneamente vários painéis não foi considerada. A solução da Heurística TC contém um número alto de padrões distintos, o que pode provocar a subutilização da seccionadora em algumas operações de corte. Se a diversidade de padrões utilizados no processo de corte é reduzida, a quantidade de vezes que os padrões escolhidos serão usados pode aumentar, o que poderá favorecer a taxa de utilização da seccionadora [YL06]. Minimizar o número de ciclos da serra é um aspecto importante para aumentar a produtividade do processo de corte.

Outro aspecto que merece atenção é o fato da Heurística TC trabalhar com uma matriz que contém várias dezenas de padrões tabuleiros compostos, sendo que a solução ótima utiliza poucos padrões. Apesar da Heurística TC apresentar tempos computacionais plenamente aceitáveis (da ordem de segundos), esse fato indica um esforço computacional desnecessário. A Heurística TC pode ser facilmente incorporada no sistema CorteBi para gerar apenas as colunas necessárias a cada iteração do método simplex.

Neste trabalho consideramos que o tamanho dos lotes para a produção dos móveis era conhecido a priori. No entanto, a perda de matéria prima depende diretamente da dimensão e da demanda dos itens. Se a produção de alguns móveis é antecipada, a demanda dos itens aumenta e é possível definir padrões de corte com índice de perda menor. Para fazer esta antecipação é necessário observar a capacidade das máquinas disponível para produção e o custo associado ao estoque de itens e móveis. A decisão das indústrias de antecipar ou não a produção de móveis envolve o acoplamento de dois problemas de otimização: o problema de corte de estoque e o de dimensionamento de lotes. Investigar modelos e métodos de solução para resolver de forma integrada estes dois problemas é outro tópico interessante para pesquisa futura (e.g. [GF06], [AM05], [SA06]). 
O sistema CorteBi está em contínua evolução tendo como perspectiva servir de protótipo para o desenvolvimento de um sistema de apoio à tomada de decisão para a indústria de móveis. A versão corrente [RL07] contém uma interface gráfica que facilita a operação do sistema e permite a visualização dos padrões de corte gerados. A inclusão de novos módulos para a geração de padrões tabuleiros composto (Seção 4) e a geração de padrões considerando a minimização de ciclos da serra está em andamento.

\section{Agradecimentos}

Agradecemos ao CNPq (proc. 473001/2004-7) e à FAPESP (proc. 2006/03496-3) pelo apoio financeiro, e à Fábrica $\mathrm{V}$ por ter cedido os dados usados neste trabalho. Agradecemos também aos dois revisores anônimos pelos valiosos comentários e sugestões.

\section{Referências Bibliográficas}

[AB05] ABIMOVEL (2005). Panorama do setor moveleiro no Brasil - Informações gerais. Associação Brasileira das Indústrias do Mobiliário, Agosto. Disponível em: $<$ http://www.movergs.com.br/arquivos/inf_set_moveleiro/panorama_abimovel_2005 v1-2.pdf> (último acesso 20/12/2008).

[AM05] Arbib, C. \& Marinelli, F. (2005). Integrating process optimization and inventory planning in cutting-stock with skiving option: An optimization model and its application. European Journal of Operational Research, 163, 617-630.

[AMY99] Arenales, M.; Morabito, R. \& Yanasse, H. (Eds.) (1999). Special issue: Cutting and Packing problems. Pesquisa Operacional, 19.

[AMY04] Arenales, M.; Morabito, R. \& Yanasse, H. (2004). Problemas de Corte e Empacotamento. In: Simpósio Brasileiro de Pesquisa Operacional, 36, 2004, Anais... São João Del Rei, 2690-2769, CD-ROM.

[BS06] Belov, G. \& Scheithauer, G. (2006). A branch-and-cut-and-price algorithm for onedimensional stock cutting and two-dimensional two-stage cutting. European Journal of Operational Research, 171, 85-106.

[Ca04] Cavali, R. (2004). Problemas de Corte e Empacotamento na Indústria de Móveis: Um Estudo de Caso. 2004, 87 f. Dissertação (Mestrado), Pós-Graduação em Matemática Aplicada, UNESP, São José do Rio Preto/SP.

[CR04] Cavali, R. \& Rangel, S. (2004). Production Planning: A Cutting Stock Problem In The Furniture Industry. In: Anais do II CLAIO, Havana. v. único. p. T137.

[Ch83] Chvátal, V. (1983). Linear Programming. W.H. Freeman and Company.

[Ci04] Cifuentes, R. (2004). Políticas de desenvolvimento setorial local: o pólo moveleiro de Votuporanga. In: Aspectos econômicos de experiências de desenvolvimento local: um olhar sobre a articulação de atores, Instituto Pólis, São Paulo, 80p.

[Ci06] Cintra, G.F. (2006). Uma Abordagem Baseada em Programação Dinâmica e Geração de Colunas para o Problema de Corte de Guilhotina Bidimensional com Placas Variadas. In: Congresso Nacional de Matemática Aplicada e Computacional, 2006, Anais... Campinas, SP, v. único, T304. 
[CM00] Carnieri, C. \& Mendoza, G. (2000). A fractional algorithm for optimal cutting of lumber into dimension parts. Annals of Operations Research, 95, 83-92.

[CMWX08] Cintra, G.F.; Miyazawa, F.K.; Wakabayashi, Y. \& Xavier, E.C. (2008). Algorithms for two-dimensional cutting stock and strip packing problems using dynamic programming and column generation. European Journal of Operational Research, 191, 61-85.

[Da04] Dash Optimization (2004). Modeling with Xpress-MP. Dash Associates, Blisworth.

[Dy90] Dyckhoff, H. (1990). A typology of cutting and packing problems. European Journal of the Operational Research, 44, 145-159.

[DF92] Dyckhoff, H. \& Finke, U. (1992). Cutting and Packing in Production and Distribution: A Typology and Bibliography. Springer-Verlag Co, Heidebelberg.

[DST97] Dyckhoff, H.; Scheithauer, G. \& Terno, J. (1997). Cutting and packing. In: Annotated Bibliographies in Combinatorial Optimization [edited by M. Amico, F. Maffioli and S. Martello], John Wiley, New York, 393-414.

[ESICUP] ESICUP - EURO Special Interest Group on Cutting and Packing. $<$ http://paginas.fe.up.pt/ esicup/> (último acesso 04/04/2007).

[Fi06] Figueiredo, A. (2006). Análise de produtividade dos padrões de corte na indústria de móveis. Dissertação, Pós-Graduação em Matemática Aplicada, UNESP, São José do Rio Preto, Brasil.

[FR06] Figueiredo, A. \& Rangel, S. (2006). Geração de padrões de corte produtivos para a indústria de móveis. In: Anais do XXXVIII SBPO, Goiânia -GO, SOBRAPO, v. único.

[GPCE] GPCE Grupo Brasileiro com interesse em Problemas de Corte e Empacotamento \& Correlatos. <http://www.simulab.uel.br/spek/gpce.html> (último acesso 04/04/2007).

[GG61] Gilmore, P. \& Gomory, R. (1961). A linear programming approach to the cutting stock problem. Operations Research, 9, 849-859.

[GG63] Gilmore, P. \& Gomory, R. (1963). A linear programming approach to the cuttingstock problem II. Operations Research, 11, 863-888.

[GG65] Gilmore, P. \& Gomory, R. (1965). Multistage cutting stock problems of two and more dimensions. Operations Research, 14, 94-120.

[GF06] Gramani, M.C.N. \& França, P.M. (2006). The combined cutting stock and lot-sizing problem in industrial processes. European Journal of Operational Research, 174(1), 509-521.

[KKS96] Klempous, R.; Kotowski, J. \& Szlachcic, E. (1996). Interactive procedures in largescale two-dimensional cutting stock problems. Journal of Computational and Applied Mathematics, 66, 323-331.

[KY04] Katsurayama, D.M. \& Yanasse, H.H. (2004). Um Algoritmo para geração de padrões tabuleiros exatos a partir de Uma Combinação dada de Itens. Anais do XXXVI SBPO.

[KY05] Katsurayama, D.M. \& Yanasse, H.H. (2005). Algoritmos para determinação de padrões tabuleiros exatos e restritos: testes computacionais comparativos. Anais do XXXVII SBPO, 1567-1578. 
[KY06] Katsurayama, D.M. \& Yanasse, H.H. (2006). Refinamento de um algoritmo enumerativo para determinação de padrões tabuleiros exatos e restritos. Anais do XXXVIII SBPO, 1694-1700.

[LG05] Landi, F.R. \& Gusmão, R. (2005). Indicadores de ciência, tecnologia e inovação em São Paulo 2004. FAPESP, São Paulo, v. 1. Capítulo 9. <http://www.fapesp.br/ indicadores2004/volume1/cap09_vol1.pdf> (último acesso em: 20/12/2008).

[LMM02] Lodi, A.; Martello, S. \& Monaci, M. (2002). Two-dimensional packing problems: a survey. European Journal of Operational Research, 141, 241-252.

[LS04] Lorenzo, H.C. \& Stipp, M. (2004). Interação entre micros, pequenas e médias empresas como estratégia de crescimento e capacitação: o pólo moveleiro de Votuporanga-SP. Interações, 6(9), 35-42, Setembro.

[MA00] Morabito, R. \& Arenales, M. (2000). Optimizing the cutting of stock plates in a furniture company. International Journal of Production Research, 38(12), 2725-2742.

[MB06] Morabito, R. \& Belluzzo, L. (2006). Optimising the cutting of wood fibre plates in the hardboard industry. European Journal of Operational Research, publicado online $12 / 06$.

[MG98] Morabito, R. \& Garcia, V. (1998). The cutting stock problem in a hardboard industry: A case study. Computers and Operations Research, 25(6), 469-485.

[Mo07] Mosquera, G.P. (2007). Contribuições para o Problema de Corte de Estoque Bidimensional. Dissertação, Pós-Graduação em Matemática Aplicada, UNESP, São José do Rio Preto, Brasil.

[MR06] Mosquera, G. \& Rangel, S. (2006). Análise de padrões de corte para a redução de ciclos da serra. In: Resumos do XXIX CNMAC, São Carlos - SP, SBMAC, v. único, p. T342.

[MT90] Martelo, S. \& Toth, P. (1990). Knapsack Problems. John Wiley \& Sons.

[PR89] Perin, C. \& Rangel, S. (1989). O problema do corte bidimensional. In: Congresso Nacional de Matemática Aplicada e Computacional, 12, 1989, São José do Rio Preto. Anais... São Carlos, SBMAC, v. 1.

[PA06] Poldi, K.C. \& Arenales, M. (2006). Heurísticas para o problema de corte de estoque unidimensional inteiro. Pesquisa Operacional, 26(3), 473-492.

[RL07] Rangel, S. \& Lemos, R.B. (2007). Manual do sistema CorteBI - Interface Gráfica. São José do Rio Preto, DCCE/UNESP, última revisão fevereiro.

[RM08] Rangel, S. \& Mosquera, G. (2008). The cutting stock problem with reduction of saw machine set ups in a small scale furniture plant. Relatório Técnico, DCCE-UNESP (submetido para publicação).

[Sep03] Secretaria de Economia e Planejamento, Governo de São Paulo (2003). Plano Plurianual 2004-2007, Capítulo V da Lei $\mathrm{n}^{\mathrm{o}} 11.605$ de 24/12/2003. $<$ http://www.planejamento.sp.gov.br/PlanOrca/PPA20042007/lei/Lei11605capituloV.pdf $>$ (último acesso em 10/05/2007).

[SA06] Silva, C.T.L. \& Arenales. M. (2006). Problemas de otimização acoplados: modelos e técnicas de resolução. In: Anais do III CLAIO, Montevideo, Uruguai, v. único. p. T55.

Pesquisa Operacional, v.28, n.3, p.451-472, Setembro a Dezembro de 2008 
[Si03] Silva, E.M. (2003). Alinhamento das estratégias competitivas com as estratégias de produção: Estudo de casos no Pólo Moveleiro de Votuporanga/SP. Dissertação, Pós-Graduação em Engenharia de Produção, USP, São Carlos, Brasil.

[SS04] Silva, E.M. \& Santos, F.C.A. (2004). Análise do alinhamento da estratégia de produção com a estratégia competitiva: estudo de casos no setor moveleiro de Votuporanga-SP. Anais do I SIMPEP, Bauru - SP, Brasil, 08 a 10 de novembro.

[St02] Stipp, M.S. (2002). Cluster industrial: O Pólo moveleiro de Votuporanga-SP (19622001). Dissertação de Mestrado, FCL-UNESP, Campus de Araraquara, SP, Brasil.

[Su00] Suzigan, W. (2000). Industrial clustering in the state of Sao Paulo. Working paper CBS-13-00(E), University of Oxford Center for Brazilian Studies, Oxford, Inglaterra.

[Va98] Vance, P.H. (1998). Branch-and-price algorithms for the one-dimensional cutting stock problem. Computational Optimization and Applications, 9, 211-228.

[YL06] Yanasse, H.H. \& Limeira, M.S. (2006). A hybrid heuristic to reduce the number of different patterns in cutting stock problems. Computers \& Operations Research, 33, 2744-275.

[YM06a] Yanasse, H.H. \& Morabito, R. (2006). A note on linear models for two-group and three-group two-dimensional guillotine cutting problems. International Journal of Production Research, 46(21), 6189-6206.

[YM06b] Yanasse, H.H. \& Morabito, R. (2006). Linear models for one-group twodimensional guillotine cutting problems. International Journal of Production Research, 44(17), 3471-3491.

[YHZ93] Yanasse, H.H.; Harris, R.G. \& Zinober, A.S.I. (1993). Uma heurística para redução do numero de ciclos da serra no corte de chapas. Anais do III ENEGEP, Florianópolis, Universidade Federal de Santa Catarina, vol.II, 879-885.

[WW02] Wang, P. \& Waescher, G. (Eds.) (2002). Special issue on cutting and packing. European Journal of Operational Research, 141(2). 